\title{
Comparison of Feminine Gender Norms among Spanish and American College Women
}

\author{
María del Pilar Sánchez-López, Isabel Cuéllar-Flores \\ Complutense University of Madrid, Madrid, Spain. \\ Email: icuellarflores@gmail.com \\ Received February 21 ${ }^{\text {st }}, 2011$; revised April $1^{\text {st }}, 2011$; accepted May $3^{\text {rd }}, 2011$.
}

\begin{abstract}
This article describes the psychometric characteristics of the Conformity to Feminine Norms Inventory (CFNI; Mahalik et al., 2005) in a group of Spanish college women $(n=383)$, and explores cross-cultural differences in feminine role norms. Factor analysis reveals a profile similar to the one obtained in the USA and, albeit differing in some aspects, in general it supports the authors' proposed structure. Reliability and corelations between subscales were adequate. Participants endorsed less traditional views toward 4 of the 8 feminine norms of the CFNI and reported significantly less conformity than comparable American students. Only the Domestic norm received greater endorsement by Spanish women in this group. The findings support the suitability of the CFNI for use in the Spanish group and establish an empirical base for future studies of Spanish femininity. Cross-country differences are discussed.
\end{abstract}

Keywords: Spanish Femininity, Gender Roles, Feminine Norms, Cultural Differences in Feminine Norms, Spanish Women

\section{Introduction}

The empirical study on the meaning of masculinity and femininity gained in importance in the 70s. Various researchers (e.g. Baucom, 1976; Bem, 1974; Heilbrum, 1976; Spence \& Helmreich, 1974) developed scales based on concepts of instrumentality-expressiveness (Parsons \& Bales, 1955), identifying masculinity and femininity with each other in terms of these independent dimensions. This marking of the boundary for femininity and masculinity in terms of social desirability is the starting point for the criticisms which appear nowadays against these new scales, since if masculinity and femininity are concepts conditioned by historical evolution and social construction, it does not seem very convenient to fix them in such a rigid background as that of instrumentality-expressiveness (Auster \& Ohm, 2000; Marsh \& Myers, 1986; Woodhill \& Samuels, 2003). Another of the limitations highlighted is that these measures examine femininity and masculinity via global indices, without taking into account the multidimensionality reflected by these concepts, both by their own theoretical definition and by the results that some researches show at the present time (Coan, 1989; Fernández, Quiroga, Olmo, \& Rodríguez, 2007; Mahalik et al.; 2003).

To overcome these limitations, and bearing in mind the importance of making gender operative, and more specifically (from a psychological perspective), evaluating what people will make of the latter (Mahalik et al., 2003; 2005) they introduced the concept of social norm into the measurement of masculineity-femininity. To define social norms, among which gender norms are to be found, Mahalik et al. (2003, 2005), they take the description of Cialdini \& Trost (1999: p. 152), which are "rules and standards that are understood by members of a group, that guide and/or constrain social behaviour without the force of laws". In this manner femininity would be a heterogeneous set of social norms on relationships, attitudes and beliefs which are deemed suitable for women are passed on by every culture and are identifiable by members of each society. The variety of gender mandates and different individual and social factors mean that each women or man identifies with some norms more than others, and is even opposed to some of them.

Starting with this conception, Mahalik et al. (2005) constructed the Conformity to Feminine Norms Inventory (CFNI), a measure which offers a series of advantages compared to the previous ones: it is an up-to-date instrument, since it was created quite recently, and incorporates a multidimensional gender viewpoint, so that it works with the "femininity" construct, not as a homogeneous entity, but a multiple one (there would be different "femininities", with which people would identify in different degrees). Moreover, in using the concept of feminine norm, what is understood by femininity is dealt with as a set of norms of behaviour, attitudes and beliefs of a prescriptive nature. These norms are considered as a sample of all the gender norms which hypothetically exist, norms depending upon the characteristics of those taking part from which the instrument was prepared (young university students, white, American and heterosexual).

\section{Drafting the Original Questionnaire on the American Population}

Constructing the original inventory (Mahalik et al., 2005) was done by following a scrupulous empirical rationally guided methodology. The authors reviewed the bibliography on traditional feminine norms and selected 32 women for a discussion group to identify the messages they had received as to how women should think, feel and act. 100 messages were sorted into 13 large groups. Finally, two focus groups of masters and doctoral students, men and women, discussed the examples identified as norms, refined the categories and drafted the items. 
The resulting categories were 12 feminine norms. Each category included 12 items, 144 altogether, and were applied to 733 female university students. After conducting the Factor Analyses, the authors arrived at an 8-factor, main axis, oblique rotated solution. Items were retained only if they loaded at $|.4|$ or higher on one factor and did not cross-load any higher than $|.3|$ on any other factor. This resulted in 84 items being retained 7 of the 8 factors coincided with the rationally elaborated categories and only one of them combined with two of them. The final result was 8 subscales labelled as Nice in Relationships, Care for Children, Thinness, Sexual Fidelity, Modesty, Involvement in Romantic Relationship, Domestic and Invest in Appearance.

The CFNI has been developed and used predominantly with white American heterosexual college students, although it has been also applied in American black women (Cole \& Zucker, 2007) and in Canadian women (Parent \& Moradi, 2010). The instrument has been used to examine its relationships with eating disorders and other clinical outcomes (Green, Davids, Skaggs, Riopel, \& Hallengren, 2008; Hurt et al., 2007; Mahalik et al., 2005).

\section{The Present Study}

In Spain, research on femininity has used, in particular, the scales for the 70s (e. g. Fernández, Quiroga, Olmo, \& Rodriguez, 2007; García-Mina, 1997; García-Vega, Fernández García, \& Rico Fernández, 2005; Mateo \& Fernández, 1991; Sebastián, 1990) but the findings obtained support, in general and in accordance with Mahalik's model (2000), multidimensionality, unsatisfactory percentage of variance accounted for, and lack of congruence between obtained factors and the dualistic model (Fernández, Quiroga, Olmo, \& Rodriguez, 2007). Research with other instruments developed in Spain (e.g. Ideology of the Sexual Role-Moya, Navas, \& Gómez-Berrocal, 1991; Questionnaire on Gender Stereotypes-López-Sáez, 1994; Questionnaire on Attitudes to Gender Equality-Sola, Martinez, \& Meliá, 2003) give more evaluation to sexist beliefs than to the degree to which a person feels identified with a gender model, and possibly this type of instrument does not detect new forms of sexism (Moya \& Expósito, 2000).

The psychometric characteristics of the CFNI and his theoretical model make it a good instrument to measure gender. In previous works (Sánchez-López, Cuéllar-Flores, Dresch, \& Aparicio, 2009) there has been an adaptation of the CFNI to general Spanish population, and the results obtained support the suitability of the CFNI as a multidimensional gender measure to be used in Spain.

The present study aims to ask whether the categories that would indentify American female university students' conformity to feminine norms match those of Spanish female university students. We intend to check the suitability of the CFNI to this group and whether the findings differ from those obtained in the USA. We hypothesized that, considering the signs of evolution towards less stereotyped approaches with regard to sexual roles in Spain (Lameiras-Fernández et al., 2002; LópezSáez, Morales, \& Lisbona, 2008; Moya, Expósito, \& Ruiz, 2000) and that gender stereotyping is higher in the features linked to the domestic role (López-Sáez, Morales, \& Lisbona, 2008), cultural differences would appear in conformity to feminine norms.

\section{Method}

\section{Participants}

383 women between the ages of 18 and 33 filled in the CFNI. They averaged 21.85 years of age $(S D=3.14)$. All participants were college students. $76 \%$ lived in the Community of Madrid, $11 \%$ in Andalusia, 5\% in Castilla la Mancha, 3\% in Murcia, and the remainder in the communities of Catalonia, Castilla-León and La Rioja, in that order from highest to lowest frequency. These women were recruited from college campuses through both classroom recruitment and snowball sampling, where existing study subjects are used to recruit more participants into the sample.

In Table 1 some of the demographic characteristics of the Spanish and US participants were shown.

\section{Instrument}

Use has been made of the Conformity to Feminine Norms Inventory (CFNI-Mahalik et al., 2005), an 84-item instrument using a 4-point scale from Strongly Disagree to Strongly Agree. The statements have been designed to measure attitudes, beliefs and behaviour associated with feminine gender roles, both traditional and non-traditional. The CFNI have 8 subscales labelled as Nice in Relationships (original sample item: "It is important to let people know they are special"), Thinness (sample item: "I would be happier if I was thinner"), Modesty (sample item: "I always downplay my achievements"), Domestic (sample item: "I enjoy spending time making my living space look nice"), Care for Children (sample item: "Taking care of children is extremely fulfilling"), Romantic Relationship (sample item: "Having a romantic relationship is essential in life"), Sexual Fidelity (sample item: "I would feel guilty if I had a one-night stand"), and Invest in Appearance (sample item: "I spend more than 30 minutes a day doing my hair and makeup"). See Table 2 for an example of the original and corresponding adapted items to the Spanish populations and Table 3 for a definition of the subscales. Internal consistency and temporal stability for the scale in the USA college population were suitable. Criterion validity was checked by means of the Bem Sex Role Inventory (BSRI-Bem, 1974) and the Feminist Identity Composite (FIC-Fischer, Tokar, Mergl, Good, Hill, \& Blum, 2000).

Information was also requested on age, sex, nationality, the city where they were living at the time, level of studies and

Table 1.

Sociodemographic characteristics of the Spanish and American participants.

\begin{tabular}{ccc}
\hline & Spain & USA \\
\hline$n$ & 371 & 733 \\
Age & & \\
Mean & 21.85 & 19.72 \\
SD & 3.14 & 2.69 \\
Age range & $18-33$ & not specified \\
Educational level & $100 \%$ Higher & $100 \%$ Higher \\
Work situation & $100 \%$ Student & $100 \%$ Student \\
\hline
\end{tabular}


Table 2 .

Example of CFNI items.

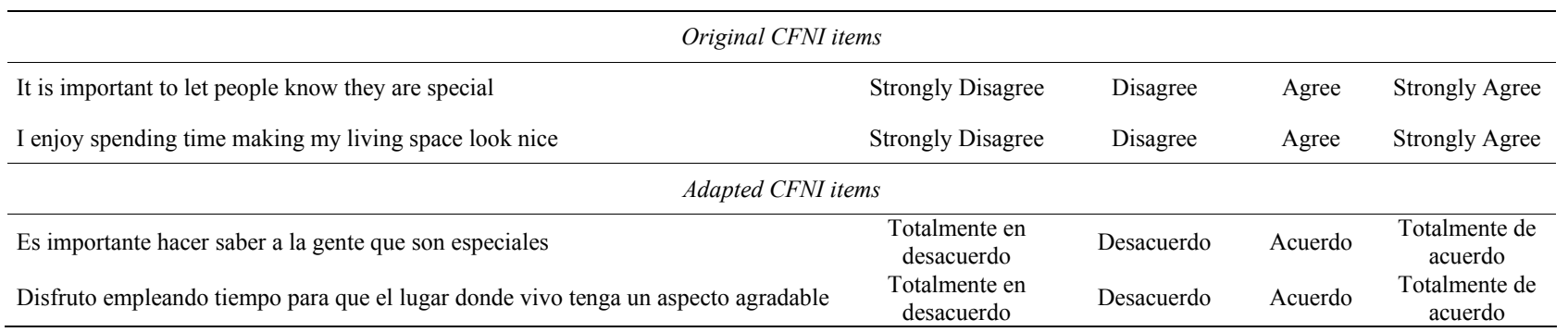

Table 3.

Definition of each of eight subscales of the conformity to feminine norms inventory.

\begin{tabular}{|c|c|c|}
\hline Factor & Subscale & Definition of feminine norm \\
\hline 1 & Nice in relationships & Develop friendly and supportive relationships with others. \\
\hline 3 & Modesty & Refrain from calling attention to one's talents or abilities. \\
\hline 4 & Domestic & Keeps house. \\
\hline 5 & Care for children & Take care and be with children. \\
\hline 6 & Romantic relationship & Invest self in romantic relationship. \\
\hline 7 & Sexual fidelity & Maintain sexual intimacy within one committed relationship. \\
\hline 8 & Invest in appearance & Commit resources to maintaining and improving physical appearance. \\
\hline
\end{tabular}

work situation.

\section{Procedure}

The process of adaptation of the CFNI to the Spanish population was done according to the recommendations of the International Test Commission's (2000) international guidelines, used previously by our research group in tests published in specialized editorials and with satisfactory results. The basic steps of this protocol are the following:

1) Translation by a bilingual psychologist, with experience in translating psychological evaluation instruments.

2) Application to a small group of expert psychologists in psychological evaluation and in adapting instruments to the reality of Spain. Evaluation is carried out as to whether the instrument has been adapted linguistically, culturally and psychologically. Agreement among the judges enables the second experimental version to be drawn up.

3) Application to a small $(n=15)$, normal population group, requesting them to indicate difficulties in comprehension, both linguistic and cultural. In this manner the third and definitive version of the instrument is obtained.

As a result of the process, minor modifications were made with the purpose of translating and adapting the questionnaire to Spanish culture and idiosyncrasy. Finally we began the applications with university women from the Spanish territory. The instrument was applied by the authors in several classes of university students from several degree courses. All the participants in our study gave their informed consent after we explained the purpose of the investigation, provided a description of the procedures of the study and alternatives to participation guaranteed their freedom to withdraw from any part of the study without any consequences. We also guaranteed the anonymity of their data. Then the participants received the questionnaire, which took fifteen minutes to answer.

\section{Results}

\section{Factor Analysis}

Principal factor extraction techniques and oblique rotation (oblimin), specifying 8 factors, were used. The scree plot showed that 8 can be a proper number of factors. This factor analysis method was used to verify the structure underlying the inventory in the group of Spanish participants because it provides the factors that explain most of the common variance, and, in addition, it assumes that the factors are related, as in the original CFNI. We used an exploratory factor analysis to check what factor structure emerges from the data, and because there has been a small alteration of actual item content for the CFNI via translation.

Before carrying out factorisation, the previous assumptions were tested: the Kaiser-Meyer-Olkin measure of sampling adequacy was .79, and Bartlett's test of sphericity was statistically significant at $p<.000$. Thus, it was possible to continue with the analysis.

The eight factor structure accounted for $37.86 \%$ of the variance of the items (against $39.51 \%$ explained by the same questionnaire-Mahalik et al., 2005) on American data, and the 
factor loading of each item appear in Table 4, where loadings below $|.30|$ have been eliminated. This is a reasonable limit for $n=383$. We can check that factor 1 explains the higher percentage of variance $(10.07 \%)$ and that items with the highest factor loading in it belong to the Care for Children subscale (11 out of 12 items). In factor 2 the items which have highest loadings belong to Thinness subscale ( 10 out of 11 items making up this subscale in the original questionnaire), and explain the $6.66 \%$ of variance. In factor 3 (explained $5.61 \%$ of the variance) items belonging to the Sexual Fidelity subscale are those showing the highest factor loadings (9 out of 10 items). In factor 4 (explained $4.44 \%$ of the variance) it is the items on the Modesty subscale ( 7 out of 9 items) and in factor 5 (explained $3.63 \%$ of the variance) those of the Domestic subscale ( 7 out of 8). In factor 6 (explained $2.80 \%$ of the variance) the items which have highest loadings belong to the subscale of Nice in Relationships (4 out of 7). The items forming part of the Invest in Apparience subscale (6 items out of 7) saturate fundamentally in factor 7 (explained $2.39 \%$ of the variance) and those of the Romantic Relationship subscale ( 8 out of 9 ) in factor 8 (explained $2.24 \%$ of the variance). The pattern of variance explained by these factors is similar to the same factors in the American data.

Likewise, the analyses show that some of the items $(59,23,61$, 38 and 1) do not seem to be sufficiently explanatory in the group of Spanish participants, because their factor loadings are lower than $|.30|$.

\section{Correlations between Subscales and Internal Consistency on the CFNI}

Cronbach's alpha coefficient has been calculated for the estimation of the reliability of the instrument and the correlations between subscales. Table 5 presents the results for the group of Spanish and American women. The alpha coefficient for the total scale is .86 and the range of values for the subscales is .72 for the lowest and .91 the highest, the average of the coefficient for the 8 scales is .79 . All values are lower in the Spanish group. As for correlations between subscales, the results indicate that all the scales have a positive, significant correlation with the total score, and there are also correlations between some of them.

\section{Differences between Spanish and USA Groups of Participants}

In Table 6 there appear the means and standard deviations of the CFNI subscales in the group of Spanish women and that of Americans and the results of the $t$ test for difference in media for independent groups. There are statistically significant differences in all subscales and in the total score except on the Modesty and Invest in Appearance subscales. The direction of the differences is from a lower score on all subscales for the Spanish women compared to the Americans but on Domestic subscale. If we go by the size effect and Cohen's guidelines (1988) we see that the size of those differences is high in total score, in Sexual Fidelity, Thinness; and moderate in Care for Children, Romantic Relationship and in Domestic. The differences are small in Nice in Relationships.

\section{Discussion}

The results of the factor analysis in the Spanish group provide a general factor structure similar to the one obtained in the USA group, but differing in some important aspects. Mahalik et al. (2005) chose those items with factor loadings equal to or higher than $|.40|$ in a factor and which did not exceed $|.30|$ in any other. Nonetheless, some authors (García, Gil, \& Rodríguez, $2000)$ consider that a factor loading equal to or more than $|.30|$ is adequate with a large size sample and this criterion would lead to a better explanation of some items in the results obtained in our study. Thus, each factor corresponds with most of the items of the factors extracted in the American data, and, consequently, with the subscales previously drawn up in a ra-

Table 4.

Principal axis oblimin rotated structural matrix, percentage of total variance for eight factors, eigenvalues and communalities.

\begin{tabular}{|c|c|c|c|}
\hline Factors & Items and corresponding factor loadings (in parenthesis) & Eigenvalue & Explained variance \\
\hline 1 & $\begin{array}{l}\text { Child } 27 \text { (.811), Child } 83 \text { (.785), Child } 19 \text { (.777), Child } 80 \text { (-.765), Child } 36 \text { (.759), Child 54(-736), } \\
\text { Child } 70 \text { (-.717), Child } 76 \text { (.688), Child 45(.666), Child } 10(-.626) \text {, App62 (-.625), Child } 2(-.575)\end{array}$ & 8.98 & 10.07 \\
\hline 2 & $\begin{array}{l}\text { Child } 64 \text { (.848), Thin } 37(.777) \text {, Thin } 3(.771) \text {, Thin } 11(-.689) \text {, Thin } 46(.674) \text {, Thin } 77 \text { (.669), Thin } \\
71(-.620) \text {, Thin } 81(-.612) \text {, Thin } 28(-.585) \text {, Thin } 55(-.447) \text {, Thin } 20(.445)\end{array}$ & 6.11 & 6.66 \\
\hline 3 & $\begin{array}{l}\text { Thin65 (-.792), Fid } 29 \text { (-.783), Fid } 47 \text { (.714), Fid } 56 \text { (.640), Fid_21 (-.619), Fid } 39 \text { (.611), Fid } 78 \\
(-.597) \text {, Fid } 4(-.587) \text {, Fid } 12(.483) \text {, Fid } 72 \text { (.451) }\end{array}$ & 5.23 & 5.61 \\
\hline 4 & $\begin{array}{l}\text { Mod } 30(.621) \text {, Fid } 57 \text { (.617), Mod } 40(-.569) \text {, Mod } 14 \text { (.566), Mod } 73 \text { (.513), Mod } 5 \text { (-.505), Mod } \\
49(-.488) \text {, Fid } 66(-.422) \text {, Mod } 22(.315)\end{array}$ & 4.34 & 4.44 \\
\hline 5 & $\begin{array}{l}\text { Dom } 51 \text { (.714), Dom16 (-.686), Dom } 24 \text { (.633), Dom } 32 \text { (-.581), Dom } 68 \text { (.576), Dom } 7 \text { (-.557), } \\
\text { Dom } 42 \text { (.542) }\end{array}$ & 3.66 & 3.63 \\
\hline 6 & $\begin{array}{l}\text { Relat } 75(.310) \text {, Relat } 69(.558) \text {, Relat } 63(-.490) \text {, Relat } 44(-.307) \text {, Relat } 35(.392) \text {, Relat } 53 \\
(-.385) \text {, Relat } 48(-.357) \text {, Relat } 79(.357) \text {, Relat } 26(-.354) \text {, Relat } 9(.350) \text {, Relat } 13(.335) \text {, Relat } 82 \\
(.328) \text {, Relat } 18(-.325)\end{array}$ & 2.98 & 2.80 \\
\hline 7 & $\begin{array}{l}\text { Appe } 34(-.763) \text {, Appe } 52 \text { (.646), Appe } 25 \text { (.585), Appe } 8 \text { (-.568), Appe43 (.564), Appe } 17 \text { (.432), } \\
\text { Rom } 60(-.423)\end{array}$ & 2.59 & 2.39 \\
\hline 8 & $\begin{array}{l}\text { Rom } 50(-.593) \text {, Rom } 31(-.593) \text {, Rom } 41(.539) \text {, Rom } 33 \quad(-.445) \text {, Rom } 67 \text { (-.358), Rom } 74 \\
(.356) \text {, Rom } 6(-.355) \text {, Relat } 84(-.348) \text {, Rom } 15(-.308)\end{array}$ & 2.50 & 2.24 \\
\hline
\end{tabular}

Note. $n=383$. Relat $=$ Nice in Relationships, Rom = Involvement in Romantic Relationship, App = Invest in Appearance, Child = Care for Children, Mod = Modesty, Dom $=$ Domestic, Fid $=$ Sexual Fidelity, Thin $=$ Thinness. 
Table 5 .

Correlations between CFNI Total and subscale scores and internal consistencies of spanish and USA groups.

\begin{tabular}{|c|c|c|c|c|c|c|c|c|c|c|}
\hline Scales & 1 & 2 & 3 & 4 & 5 & 6 & 7 & 8 & Spain $\alpha$ & USA $\alpha$ \\
\hline 1. Relation & 1 & & & & & & & & .72 & .84 \\
\hline 2. Children & $.391 * *$ & 1 & & & & & & & .91 & .92 \\
\hline 3. Thinness & -.001 & .019 & 1 & & & & & & .88 & .90 \\
\hline 4. Fidelity & .095 & $.142 * *$ & -.025 & 1 & & & & & .86 & .85 \\
\hline 5. Modesty & $-137 * *$ & -.012 & .044 & $.157 * *$ & 1 & & & & .74 & .82 \\
\hline 6. Romantic & $.249 * *$ & $.203 * *$ & $.130^{*}$ & $.259 * *$ & $-141^{* *}$ & 1 & & & .72 & .77 \\
\hline 7. Domestic & $.120^{*}$ & $.159 * *$ & .006 & $.236^{* *}$ & .045 & $.114^{*}$ & 1 & & .77 & .84 \\
\hline 8. Appearanc & .051 & -.084 & $.201 * *$ & $.120^{*}$ & -.067 & $.146^{* *}$ & $.161^{* *}$ & 1 & .78 & .82 \\
\hline TOTAL & $.540^{* *}$ & $.596^{* *}$ & $.430 * *$ & $.537 * *$ & $.174 * *$ & $.512 * *$ & $.433^{* *}$ & $.346^{* *}$ & .86 & .88 \\
\hline
\end{tabular}

Note. ${ }^{*}$ Significant correlation at the level of $.01\left(2\right.$-tail), ${ }^{*}$ Significant correlation at the level of .05 (2-tail), Relation $=$ Nice in Relationships, Romantic $=$ Involvement in Romantic Relationship, Appearanc $=$ Invest in Appearance, Children $=$ Care for Children, Fidelity $=$ Sexual Fidelity, USA $\alpha=$ Mahalik et al. $(2005)$.

Table 6.

Means, Standard Deviations and $t$ Values on CFNI subscales comparing Spanish and USA participants.

\begin{tabular}{|c|c|c|c|c|}
\hline & Spanish Group $(n=383)$ Mean (SD) & USA Group $(n=733)$ Mean $(\mathrm{SD})^{\mathrm{a}}$ & $t$ & $d$ (effect size) \\
\hline 1. Relationships & $37.99(5.36)$ & $39.48(5.97)$ & $-4.09 * * *$ & 0.26 (low) \\
\hline 2. Care for Children & $22.23(6.53)$ & $26.51(6.24)$ & $-10.70 * * *$ & 0.66 (medium) \\
\hline 3. Thinness & $15.29(6.19)$ & $20.87(6.18)$ & $-14.31 * * *$ & 0.90 (high) \\
\hline 4. Sexual fidelity & $14.85(5.43)$ & $20.22(5.55)$ & $-15.46^{* * *}$ & 0.97 (high) \\
\hline 5. Modesty & $12.60(3.35)$ & $13.02(3.67)$ & 1.86 & \\
\hline 6. Romantic & $13.79(3.67)$ & $15.64(3.73)$ & $-7.90 * * *$ & 0.49 (medium) \\
\hline 7. Domestic & $15.42(3.45)$ & $14.10(3.10)$ & $6.49 * * *$ & 0.40 (medium) \\
\hline 8. Appearance & $11.87(3.59)$ & $12.01(3.75)$ & n.s. & \\
\hline Total & $144.06(17.58)$ & $162.73(18.26)$ & $-16.42 * * *$ & 1.04 (high) \\
\hline
\end{tabular}

Note. $* * * p=.000$, Relationships $=$ Nice in Relationships, Romantic $=$ Investment in Romantic Relationships, Appearance $=$ Investment in Appearance, $n s=$ nonsignificant, ${ }^{a}$ Mahalik et al. (2005).

tional manner.

However, there are some factors that include items stemming from several scales in the original. There would be factors made up of items which in Spanish women would be related to different subscales and some items that do not seem to be sufficiently explanatory in this group, because their factor loadings are lower than $|.30|$. Furthermore, the majority of these last items are related to the most extreme type of statements, or with what would be least "acceptable" to state, for example, the items "I don't care if my living space looks messy" (item 61) on the Domestic subscale, or "I pity people who are single" (item 23) of Romantic Relationship, compared to other items which belong the same subscales but saturate on different factors, such as "It is important o keep your living space clean" (item 7) on Domestic or "I can be happy without being in a romantic relationship" (item 41), from Romantic Relationship. On the other hand, items corresponding to the subscales Nice in
Relationships and Romantic Relationship have factor loadings higher than $|.30|$ in two different factors (6 and 8). Thus, in Spanish women, orientation towards relationships, either romantic or non-romantic ones, would be more related. These results, therefore, do not invalidate the theoretical structure proposed in the original, rather they may indicate that among Spanish women some items are not sufficient suitable and suggest that may be deleted.

The results of the factor analyses and of the correlations between scales confirm, in general, previous findings (SánchezLópez, Cuéllar-Flores, Dresch, \& Aparicio, 2009) and the model proposed by the author (Mahalik, 2000; Mahalik et al., 2003, 2005), according to which femininity is proposed as a multidimensional construct made up of several gender norms which are differentiated but not related, since the 8 scales are related by the total score in an intense manner and among some pairs in a moderate, low or non-significant way. Moreover, the 
analyses on the reliability of the instrument enable it to be said that the internal consistency is acceptable, the Cronbach's alpha values for each of the scales, even when lower than those of the USA group, are all above .70. Therefore we can state that the questionnaire is sufficiently uniform and consistent in our data.

Spanish women's sense of femininity, based on the findings, is similar to American college women's sense of femininity, since the categories that would identify young American women's conformity to femininity match those of young Spanish women. However, as predicted, some differences exist in terms of the degree of conformity by one group or the other. Spanish women score less on the subscales evaluating interest in romantic relationships, adjustment to the canons of thinness, care of children and sexual fidelity than American female college students, but Spanish women have greater score on the subscale evaluating home-loving. With regard to the interest in friendly relationships, the findings show that the magnitude of differences is small, albeit significant, whereas there are no differences in items related to modesty and concern for one's own image or appearance. These discrepancies could be explained by the influence of cultural factors, since both groups share other sociodemographic characteristics such as being university students and being of similar age. Thus, it is possible to discard other types of factors as sexual orientation or socioeconomic factors, and this aspect, nonetheless, would have to be confirmed in later works. In any case, the data show that the Spanish university women are less conformist to feminine norms than American student women. It is important to mention the enormous changes produced in Spain in the last decades, in part due to the great influence of the historical events and the recent fight for basic women rights. In fact, gender-role stereotyping shows a marked decline between 1993 and 2001 (López-Sáez, Morales, \& Lisbona, 2008). Making Spanish society aware of the impact of violence against women and the rights of homosexuals; as well as the large amounts of money spent on equal opportunities for men and women (for the period 2008-2011, in Spain, there has been invested 3690 million of euros (Prieto, Blasco, \& López, 2008) may have had an influence on the reduction in the degree of agreement with traditional masculinity. Moreover, a possible relationship could be proposed between the Spanish birth rate (one of the world's lowest and one which has shown a rapid fall in a short time; CIA, 2008), and the results obtained in this work with regard to conformity with norms related to childcare (fewer among the Spanish). Spanish women could be more aware of the feminine norms' "costs" and, in fact, be less conformist to them. The fact that the Domestic norm was the only norm on which Spanish women reported greater conformity than American women suggests that it may indeed represent one key aspect of Spanish feminine gender-role socialization. Regarding roles, LópezSáez, Morales, \& Lisbona (2008) confirm that gender stereotyping is higher in the features linked to the family - where the role assigned to women is still very traditional - than in other aspects like paid work.

\section{Conclusion}

Corroboration is provided, from the factor analysis, of the correlations matrix and the reliability index that the CFNI can be used with the Spanish population, and confirmation is pro- vided, as proposed by the authors (Mahalik et al., 2005), that the characteristics of the participants on the basis of which the instrument was constructed have an influence on the particularities of the results of the measurement, though, in essence, a similar organisation and a suitable model are maintained. This is particularly important because available research with the CFNI has been conducted primarily with respondents from the American culture.

Cross-country variability in the degree of the conformity to some feminine norms found in this study suggests that Spanish female college students are less traditional than American female college students, at least as operationalized by American standards of femininity. It is important, however, to notice that traditional femininity ideology should vary from culture to culture.

Our participants were chosen for their characteristics, which were the same as those Americans taking part, but limit the possibilities of generalising to any other type of population. Another limitation is that among Spanish women some items are not sufficient suitable and it could be important to delete them and check the resultant outcome. In addition, examination of validity evidence (such as criterion validity) seems fundamental, thus, this is a further limitation of this study and must be investigated in the future. Among our future prospects we would like, therefore, to continue checking possible differences on the basis of other variables, such as socioeconomic levels, age and educational levels, following the recommendations of the authors (Mahalik et al., 2005).

\section{References}

Auster, C. J., \& Ohm, S. C. (2000). Masculinity and Femininity in Contemporary American Society: A reevaluation using the bem sex-role inventory, Sex Roles, 43, 499-528. doi:10.1023/A:1007119516728

Baucom, D. H. (1976). Independent masculinity and femininity scales on the California psychological inventory. Journal of Consulting and Clinical Psychology, 44, 876. doi:10.1037/0022-006X.44.5.876

Bem, S. (1974). The measurement of psychological androgyny. Journal of Consulting and Clinical Psychology, 42, 155-162. doi: $10.1037 / \mathrm{h} 0036215$

CIA (2008). The 2008 world factbook. Washington: Central Intelligence Agency.

Cialdini, R. B., \& Trost, M. R. (1999). Social influence: Social norms, conformity, and compliance. In D. Gilbert, S. Fiske and G. Lindzy (Eds.), The handbook of social psychology (Vol. 2). Boston: McGraw-Hill.

Coan, R. W. (1989). Dimensions of masculinity and femininity: A self-report inventory. Journal of Personality Assessment, 53, 816-826. doi:10.1207/s15327752jpa5304_17

Cohen, J. (1988). Statistical power analysis for the behavioral sciences. Hillsdale, NJ: Lawrence Earlbaum Associates.

Cole, E. R., \& Zucker, A. N. (2007). Black and white women's perspectives on femininity. Cultural Diversity and Ethnic Minority Psychology, 13, 1-9. doi:10.1037/1099-9809.13.1.1

Fernández, J., Quiroga, M. A., Olmo del, I., \& Rodríguez, A. (2007). Escalas de masculinidad y feminidad: Estado actual de la cuestión (Masculinity and femininity scales: The present state of affairs). Psicothema, 19, 357-365.

Fischer, A. R., Tokar, D. M., Mergl, M. M., Good, G. E., Hill, M. S., \& Blum, S. A. (2000). Assessing women's feminist identity development: Studies of convergent, discriminant, and structural validity. Psychology of Women Quarterly, 24, 15-29. doi:10.1111/j.1471-6402.2000.tb01018.x 
García, E., Gil, J., \& Rodríguez, G. (2000). Análisis factorial (Factorial Analysis). Cuadernos de Estadística 7. Madrid: La Muralla.

García-Mina, A. (1997). Analysis of gender role stereotypes. Transcultural validation of the sexual role inventorystereotypes. Doctoral Thesis, Madrid: Universidad Pontificia Comillas.

García-Vega, E., Fernández, G. P., \& Rico, F. R. A. (2005). Género y sexo como variables moduladoras del comportamiento sexual en jóvenes universitarios (Gender and sex as modulatory variables of sexual behaviour in young university students). Psicothema, 17, 49-56.

Green, M. A., Davids, C. M., Skaggs, A. K., Riopel, C. M., \& Hallengren, J. J. (2008). Femininity and eating disorders. Eating Disorders, 16, 283-293. doi:10.1080/10640260802115829

Heilbrum, A. B. (1976). Measurement of masculine and feminine sex roles identities as independent dimensions. Journal of Consulting and Clinical Psychology, 44, 183-190. doi:10.1037/0022-006X.44.2.183

Hurt, M. M., Nelson, J. A., Turner, D. L., Haines, M. E., Ramsey, L. R., Erchull, M. J., et al. (2007). Feminism: What is it good for? Feminine norms and objectification as the link between feminist identity and clinically relevant outcomes. Sex Roles, 57, 355-363. doi:10.1007/s11199-007-9272-7

Lameiras-Fernández, M. L., Lopez, W. L., Rodríguez-Castro, Y., Dávila, M. L., Lugo, I., Salvador, C. M., Mineiro, E., \& Granejo, M. (2002). Ideology of the sexual role in Latin American countries. Progress in Latin american Clinical Psychology, 20, 37-44.

López-Sáez, M. (1994). Cultural and individual processes involved in gender stereotypes an empirical approach to career choice. Revista de Psicologia Social, 9, 213-230.

López-Sáez, M., Morales, J. F., \& Lisbona, A. (2008). Evolution of gender stereotypes in Spain: Traits and roles. The Spanish Journal of Psychology, 11, 609-617.

Mahalik, J. R. (2000). A model of masculine gender role conformity. Symposium-Masculine gender role conformity: Examining theory, research, and practice. $108^{\text {th }}$ Annual Convention of the American Psychological Association, Washington DC.

Mahalik, J. R., Locke, B., Ludlow, L., Diemer, M., Scott, R. P. J., \& Gottfried, M. (2003). Development of the conformity to masculine norms inventory. Psychology of Men and Masculinity, 4, 3-25. doi:10.1037/1524-9220.4.1.3

Mahalik, J. R., Morray, E. B., Coonerty-Femiano, A., Ludlow, L. H., Slattery, S. M., \& Smiler, A. (2005). Development of the conformity to feminine norms inventory. Sex Roles, 52, 417-435. doi:10.1007/s11199-005-3709-7

Marsh, H. W., \& Myers, M. (1986). Masculinity, femininity, and androgyny: A methodological and theoretical critique. Sex Roles, 14, 397-430. doi:10.1007/BF00288424

Mateo, M. A., \& Fernández, J. (1991). The dimensional nature of concepts of masculinity and femininity. Investigaciones Psicológicas, 9, 95-116.

Moya, M., \& Expósito, F. (2000). Precedents and consequences of neosexism in males and females in the same workplace. In D. Caballero, M. Méndez and J. Pastor (Eds.), La mirada psicosociológica (pp. 619-625). Madrid: Biblioteca Nueva. doi:10.1023/A:1007094232453

Moya, M., Expósito, F., \& Ruiz, J. (2000). Close relationships, gender and career salience. Sex Roles, 42, 825-846.

Moya, M., Navas, L., \& Gómez-Berrocal, C. (1991). Ideological scale of the sexual rolel. Actas del Congreso de Psicología Social de Santiago de Compostela, 86, 554-566.

Parent, M. C., \& Moradi, B. (2010). Confirmatory factor analysis of the confomirty to feminine norms inventory and development of an abbreviated version: The CFNI-45. Psychology of Women Quarterly, 34, 97-109. doi:10.1111/j.1471-6402.2009.01545.x

Parsons, T., \& Bales, R. F. (Eds.) (1955). Family, socialization and interaction process. New York: Free Press.

Prieto, J. M., Blasco, R., \& Montalvo G. L. (2008). The discreet charm of being a male. Papeles del Psicólogo, 29, 229-241.

Sánchez-López, M. P., Cuéllar-Flores, I., Dresch, V., \& Aparicio, M. E. (2009). Conformity to feminine norms in Spanish population. Social Behavior and Personality: An international journal, 37, 1171-1186.

Sebastián, J. (1990). Scales of masculinity and femininity: Underlying assumptions to the classical and present day model. Evaluación Psicológica, 6, 133-153.

Sola De, A., Martinez, B. I., \& Meliá, J. L. (2003). The questionnaire on attitudes to gender equality (CAIG): Preparation and pyschometric study. Anuario de Psicologia, 34, 101-123.

Spence, J. T., \& Helmreich, R. L. (1974). The personal attributes questionnaire: A measure of sex roles stereotypes and masculinity-femi-ninity. Journal of Personality and Social Psychology, 64, 624-635. doi:10.1037/0022-3514.64.4.624

Woodhill, B. M., \& Samuels, C. A. (2003). Positive and negative androgyny and their relationship with psychological health and well-being. Sex Roles, 48, 555-565. doi:10.1023/A:1023531530272 